\title{
MEASURING THE EFFECTS OF MARKETING EXPENSES AND EXTERNAL FACTORS ON HOUSING SALES TRANSACTIONS
}

\author{
DOI: 10.17261/Pressacademia.2019.1039 \\ JBEF- V.8-ISS.2-2019(1)-p.82-92
}

\author{
Mehmet Emre Camlibel ${ }^{1}$, Ali Hepsen ${ }^{2}$, Olgun Aydin ${ }^{3}$ \\ ${ }^{1}$ Bogazici University, Civil Engineering Department, Istanbul, Turkey. \\ emre.camlibel@re-pie.com, ORCID: 0000-0002-4095-9377 \\ ${ }^{2}$ Istanbul University, School of Business, Department of Finance, Istanbul, Turkey. \\ ali.hepsen@istanbul.edu.tr, ORCID: 0000-0002-3379-7090 \\ ${ }^{3}$ Mimar Sinan University, Institute of Science, Department of Statistics, Istanbul, Turkey. \\ olgun.aydin@ogr.msgsu.edu.tr, ORCID: 0000-0002-7090-0931
}

Date Received: April 10, 2019

Date Accepted: May 12, 2019

To cite this document

Camlibel, M. E., Hepsen, A., Aydin, O.,(2019). Measuring the effects of marketing expenses and external factors on housing sales transaction. Journal of Business, Economics and Finance (JBEF), V.8(2), p.82-92, DOI: 10.17261/Pressacademia.2019.1039

Permemant link to this document: http://doi.org/10.17261/Pressacademia.2019.1039

Copyright: Published by PressAcademia and limited licenced re-use rights only.

\begin{abstract}
Purpose- In recent years, with the support of urban regeneration movements, the real estate sector has become one of the locomotive sectors in terms of economic and social development, particularly for the developing countries. When the real estate sector is examined, it is seen that the housing sector, which directly touches to the end user and is considered sometimes for use sometimes for the investment purposes, comes to the forefront. It is observed that the competition among the developer firms also increased in parallel with the investments made. In this study, the 2004-2017 period was examined, the statistical models were created to help the developers in developing the housing marketing strategies, the marketing strategies affecting the house sales trends and the external factors were highlighted. Our paper is the first academic study that identifies this relationship in Turkish housing market.

Methodology- Within the scope of this study; R programming language and Wilcoxon Rank was used to analyze the different housing marketing campaigns of one of the pioneer real estate firms in Turkey and their effect on the sales figures; the rank sum test was conducted; and, the VAR models were constructed and Impulse Response analysis, Pearson Correlation Coefficient were used for the relationship analyses.

Findings- According to the results of the study, it is seen that the social events, long-term holidays, rainfall and snowfall, campaigns of the competitors have no statistically significant effect on the net sales and gross income. However, it was determined that the Ramadan period and the digital marketing had a significant effect on the net sales and gross income. It is determined that the use of outdoor billboard, which is expected to affect the housing sales, was inversely proportional to the net sales and gross income, that is, it had a negative effect when applied. Conclusion- It is thought that this study can be more improved as a result of including the followings into the model: more detailed classification of the social events, remodeling the Ramadan periods according to either they coincide with the summer month or the winter month, assessment of the effect of rainfall and snowfall considering the climate zone Turkey is in, more detailed analysis of the effect of the campaign of competitors, that the effect of digital marketing will be higher as the technology develops.

It is expected that the modeling of the findings reached in this study (or which will be detailed in later studies) by using an algorithm will provide a cost-benefit optimization.
\end{abstract}

Keywords: Housing sector, marketing costs, marketing, housing sales transaction, modelling.

JEL Codes: 018, M31, C52

\section{INTRODUCTION}

Breaking a record for the annual house sales with 936,215(TUIK, House Sales Statistics) house sales in 2017, the Turkish real estate sector has achieved a significant growth in the last 10 years despite the local and global fluctuations with the changing demographic structure of the country, the developing macroeconomic indicators, and the need for earthquake-oriented urban transformation. In Turkey, the population, of which was the third largest population of the Europe, grew $1.25 \%$ to reach 81 million in 2017(TUIK, Population Statistics), the population growth rate constitutes one of the most important dynamics of the 
housing sector. With the effect of the household size falling to 3.5(TUIK, Household Statistics) in 2017, the number of the households increased by 5,5 million in the last 10 years. In other words, only these two factors caused the need for approximately 550,000 housing to arise per year. If the internal and external migrations received by the metropolises are considered together with the increasing urbanization rate, the calculated housing need will increase to over 550,000 per year.

Table 1: Population, Household Size, and the Number of Household by Years

\begin{tabular}{cccc}
\hline Year & Population (Million) & Household Size & No. of Household (Million) \\
\hline 2017 & 81.0 & 3.5 & 23.4 \\
\hline 2007 & 70.5 & 4.0 & 17.6 \\
\hline 2004 & 68.0 & 4.0 & 17.0 \\
\hline
\end{tabular}

Having an economic size of $\$ 392$ billion in 2004 and reaching an economic size of $\$ 851$ billion by increasing more than twofold in 2017, Turkey's economy was the 18th largest economy in the world and the 8th largest economy in Europe as of 2017(World Bank). According to the report of PwC titled "The World in 2050," it was estimated that Turkey would become the 14th largest economy in the world (PWC, 2015) At the same time, the national income per capita, which was $\$ 5,818$ in 2004 , has increased by nearly twofold in 2017 and reached to $\$ 10,540$ (TUIK). Increased by the similar positive macroeconomic data, the level of welfare also caused an increase in demand in the housing sector between 2004 and 2017. After the Marmara earthquake in 1999 , the better management of the disaster risk emerged as a necessity, consequently many construction specifications and building related codes were amended from 2001 onwards, and eventually in 2012 the urban transformation thrust came in force with "the Law on Transformation of the Disaster Risky Areas (Act. No. 6306)." In this context, 14 million houses were intended to be transformed in the next 20 years, and the construction cost of this transformation was estimated to be around $\$ 500$ billion (TUIK). Given the dynamics in question, it is expected that in the long term the Turkish housing sector will continue to grow, and the housing demand will at least keep the current level because of the ongoing demand and need but with new housing companies entering the market the housing sales in the metropolises will be subject to a serious competition that increases every year. With this increased competition, the new technologies, and innovative marketing methods; on which fields the marketing budgets will be used has become a key issue in terms of both the project cost budgets and the sales and cash flow success. In the current situation, the housing developers are open to trying new methods, but they do not keep applications details and results of these practices in a data bank and do not carry out an optimization (or any other type of) modelling or analysis. The aim of this study was, in this competitive environment, to statistically measure the impact of the different marketing activities and external factors on the housing sales and to ensure that the marketing budget expenditures are optimized according to these factors. The housing developers and marketing consultants will be able to review the sample case and have an idea about how to approach the challenge and maybe also if the case matches their situation; on which marketing activity and in which proportion and how often they should allocate the budget.

\section{LITERATURE REVIEW}

Real estate development, including hosing development, is an idea that comes to completion and use the bricks and mortar put in place by the development team. This definition implies that the real estate development is not a single or a simple activity. It is a long-term continuing process including different types of activities such as marketing. "Marketing" is a social and managerial process by which individuals and groups obtain what they need and want through creating, offering, and exchanging products of value with others. The classic definition of marketing should be altered to the nature of real estate, it would be defined as marketing of real estate is a social and managerial process by which individuals and groups obtain what they need and want through offering and exchanging land; and creating, offering and exchanging buildings directly and indirectly to others. In literature, related to marketing, most studies analyze sales advertising in the housing market by selecting a correct method to target the consumer in a successful manner (Terri, 2003 and Miles et. al, 2001).

Especially literature review analyzing the relation between Turkish real estate market and marketing consists of important studies. For instance, Polat and Ferman (2015) presented the factors of marketing practice and applications of 'branded housing projects' around the Istanbul metropolitan area. They noted that customer satisfaction and corporate structure are perceived to be the most important factors resulting in marketing success when considering the importance of the factors. Competitive structure and market conditions are both determined as relatively less important factors leading to marketing performance. In addition, Cengel (2006) mentioned that for increasing sales construction firms should implement customer-oriented marketing strategies initially. In addition, image and prestige studies regarding the sector should be organized. In the long-run, as a tool to identify services from each other, the firms within the sector should move towards "branding". Komurlu et. al (2013) found that development and marketing strategies for residential construction depends on buyers' preferences. Their study focused on 
developers' perceptions of buyers' preferences. Nine factors, including economic factors, developer brand, location, means of transportation, architectural functions, existence of social facilities, legal issues, quality of construction, and compliance with seismic codes, are investigated and ranked using the analytic hierarchy process (AHP). They indicated that developers perceive the price of the property, the quality of the developer, and the location of the property to be the three most important buyer preferences. On the other hand, Cizmeci and Ercan (2015) presented that for housing companies in Turkey, marketing tools that create "paid digital content" (corporate web site, search engine pages, e-mail communication, etc.) had a greater impact than those which created "proactive content" (social media, etc.). Researchers also found that there was consensus among the housing companies in the creation of brand awareness, digital marketing tools such as Facebook or Twitter which create the latter content will become more important in the future.

\section{DATA AND METHODOLOGY}

Within the scope of the study, the data belonging to the years between 2004 and 2017, which was recorded regularly by the sales directorate for the housing projects of a pioneer firm operating in the real estate and different sectors in Turkey, was used.

The following variables constitutes the inputs of the study:

Social events, The month of Ramadan, Long holidays, Exam periods, Present month, Square meter price, Average temperature, Precipitation situation, Campaigns of the competitors, Advertising in the main newspaper and its cost, Advertising on TV and its cost, Advertising on the thematic (news) TV channels and its cost, Digital advertising and its cost, Advertising on the billboard and its cost, and Total marketing cost.

The following variables was used as the output: Net housing sales and Gross income

Within this scope, first the preliminary analyses were made and then the modeling studies were conducted in line with the relationship analysis. All analyses were conducted in the $\mathrm{R}$ environment, an open source statistical programming language. Descriptive statistics and the Wilcoxon Rank Test were used for the preliminary analyses. The Wilcoxon Rank Test was developed by Frank Wilcoxon as a nonparametric test called rank-sum test. The test is assigned to all points evaluated as a group and then grades the ranks of each group. The null hypothesis is that two samples come from the same population, and so any difference in the two rank-sums arises from the sampling error only. The rank-sum test is generally defined as a nonparametric version of the t test for two independent groups (Kerby, 2014). For the relationship analyses, Vector Auto Regression (VAR) models were established and Impulse/Response analyses were made. Then, Pearson Correlation Coefficients were calculated to measure the power of the linear relationship between the variables. VAR models are easy to use for the analysis of multivariate time series. It is a dynamic multi-variable natural extension of the univariate autoregressive model. VAR models are often used to estimate the dynamic behavior of the econometric and financial time series (Pesaran, 1998). The impulse/response analysis is the measurement of the expected effect of the shocks in a variable at a given time on the other variables. The Pearson correlation coefficient, also called the Pearson $r$ or Pearson product-moment correlation coefficient (PPMCC), is a measure of the linear dependence (correlation) between the $X$ and $Y$ variables. It has a value between +1 and -1 , where 1 is total positive linear correlation, 0 is linear correlation, and -1 is total negative linear correlation (Stigler, 1989).

When the number of housing sales were modeled in the modeling studies, the count regression models were applied here. The classic Poisson and negative binomial regression models, which are used for the cases where the dependent variable is discrete, belong to the family of generalized linear models (Zeileis, 2008). The Poisson model assumes that the mean is equal to variance with an assumption that is often violated. The NB model has a greater built-in distribution parameter, variance of which can be calculated, than the mean value generated by the unobserved and/or temporal dependence (Chin, 2003).

\section{FINDINGS AND DISCUSSIONS}

When the average of net sales and gross income is examined according to whether there are social events, as it is understood from the Table 2, it can be stated that the social mobility does not create a negative effect on sales. The Wilcoxon Rank test was applied, and it was tested whether the difference between the two periods was statistically significant. According to the results in the Table 3, there is no statistically significant difference between the gross income and net sales between these two periods. These social events are not the events seriously affecting the clear majority of the population such as earthquakes, coups, and warfare but the temporary and local events such as election and terrorism. In the future studies, this analysis can be repeated by classifying the social events in detail. 
Table 2: Effect of the Social Events on the Net Sales and Gross Income

\begin{tabular}{ccc}
\hline Social Events & Gross Income (Mean Value-TL) & Net Sales (Mean Value) \\
\hline No & $2,351,892$ & 7.564103 \\
\hline Yes & $2,822,962$ & 8.153846 \\
\hline
\end{tabular}

Table 3: Wilcoxon Rank Test for Measuring the Effect of the Social Events on the Net Sales and Gross Income

\begin{tabular}{ccc}
\hline Social Events & Gross Income (Mean Value-TL) & Net Sales (Mean Value) \\
\hline No & $2,351,892$ & 7.564103 \\
\hline Yes & $2,822,962$ & Wilcoxon Rank Test \\
\hline W & 285.5 & 323 \\
\hline P Value & 0.4973 & 0.1463 \\
\hline
\end{tabular}

When the effect of Ramadan on net sales and gross income average is examined, as it can be understood from the Table 4, it can be stated that the month of Ramadan period has a negative effect on the sales. The effect of the Ramadan period can vary depending on whether the month of Ramadan coincides with summer or winter. In the future studies, this analysis can be repeated by classifying this subject in detail. The effect of the Ramadan period should be considered along with the expectation of a long holiday and its preparation. Some housing firms tried to reduce the negative effect of this period by inviting to an iftarmeal (fast-breaking meal) or revising their working hours in the sales offices, but it did not provide any benefit.

Table 4: Effect of the Ramadan Period on the Net Sales and Gross Income

\begin{tabular}{ccc}
\hline Month of Ramadan & Gross Income (Mean Value-TL) & Net Sales (Mean Value) \\
\hline No & $2,581,558$ & 8.104167 \\
\hline Yes & $1,126,875$ & 3 \\
\hline
\end{tabular}

The Wilcoxon Rank test was applied, and it was tested whether the difference between the Ramadan period and the other periods was statistically significant. According to the results in the Table 5, it is possible to state that there is a statistically significant difference between the net sales in the Ramadan period and in the other periods. During the Ramadan period, the net sales decrease compared to the other periods. It cannot be indicated that there is a statistically significant difference between the Ramadan period and the other periods in terms of gross income.

Table 5: Wilcoxon Rank Test for measuring the Effect of the Ramadan Period on Net Sales and Gross Income

\begin{tabular}{ccc}
\hline Month of Ramadan & Gross Income (Mean Value-TL) & Net Sales (Mean Value) \\
\hline No & $2,581,558$ & 8.104167 \\
\hline Yes & $1,126,875$ & 3 \\
\hline W & Wilcoxon Rank Test & 40 \\
\hline P Value & 48 & 0.05358 \\
\hline
\end{tabular}

The effects of the long holiday periods on the net sales and gross income were examined and the results are shown in Table 6. Looking at the Table 6, it is seen that the long holiday periods do not have a significant effect on the gross income and net sales. However, it should be tested whether this difference is statistically significant. Therefore, the Wilcoxon Rank test was applied, and it was tested whether the change between the two periods was statistically significant. 
Table 6: Effect of the Long Holidays on the Net Sales and Gross Income

\begin{tabular}{ccc}
\hline Long Holidays & Gross Income (Mean Value-TL) & Net Sales (Mean Value) \\
\hline No & $2,559,102$ & 7.883721 \\
\hline Yes & $2,042,319$ & 6.888889 \\
\hline
\end{tabular}

Looking at the Table 7, it can be stated that the long holiday periods do not influence the gross income and net sales. It is possible to state that there is no statistically significant difference between the net sales and gross sales during long holiday periods. With which season the long holidays coincide is an important factor. It is possible that the effect of the long holidays coinciding with to the summer season when the schools are on holiday may be different from the others.

Table 7: Wilcoxon Rank Test for measuring the Effect of the Long Holidays on the Net Sales and Gross Income

\begin{tabular}{ccc}
\hline Long Holidays & Gross Income (Mean Value-TL) & Net Sales (Mean Value) \\
\hline No & $2,559,102$ & 7.883721 \\
\hline Yes & $2,042,319$ & 6.888889 \\
\hline W & Wilcoxon Rank Test & 182 \\
\hline P Value & 177 & 0.7801
\end{tabular}

When the effect of rainfall and snowfall on the net sales and gross income average is examined, according to the results in the Table 8, it can be stated that the rainfall and snowfall do not have a negative effect on the sales. The Wilcoxon Rank test was applied to test whether the difference in the gross income and net sales was statistically significant between the rainy or snowy days and the no rainfall days.

Table 8: Effect of the Rainfall and Snowfall on the Net Sales and Gross Income

\begin{tabular}{ccc}
\hline Rainfall and Snowfall & Gross Income (Mean Value-TL) & Net Sales (Mean Value) \\
\hline No & $2,139,722$ & 6.64 \\
\hline Yes & $2,775,156$ & 8.703704 \\
\hline
\end{tabular}

Looking at the Table 9, it is possible to state that there is no statistically significant difference between the snowy or rainy days and no rainfall days in terms of the net sales and gross income. These results should be interpreted by taking the climate zone Turkey is in and the examined years into consideration, it should be known that the pluvial periods last a short time and the precipitation intensity is not high.

Table 9: Wilcoxon Rank Test for Measuring the Effect of the Rainfall and Snowfall on the Net Sales and Gross Income

\begin{tabular}{ccc}
\hline Rainfall and Snowfall & Gross Income (Mean Value-TL) & Net Sales (Mean Value) \\
\hline No & $2,139,722$ & 6.64 \\
\hline Yes & $2,775,156$ & 8.703704 \\
\hline W & Wilcoxon Rank Test & 411.5 \\
\hline P Value & 418 & 0.1737
\end{tabular}

The effect of the campaigns of competitors on the net sales and gross income averages was examined and the results in the Table 10 were obtained. It can be stated that the campaigns of competitors do not have a statistically significant negative effect on the net sales and gross income of the firm concerned. 
Table 10: Effect of the Campaigns of Competitors on the Net Sales and Gross Income

\begin{tabular}{ccc}
\hline Campaigns of Competitors & Gross Income (Mean Value-TL) & Net Sales (Mean Value) \\
\hline No & $2,494,937$ & 8.1 \\
\hline Yes & $2,463,640$ & 7.619048 \\
\hline
\end{tabular}

The Wilcoxon Rank test was applied and it was showed whether the difference in the gross income and net sales is statistically significant between the days when the competitors run a campaign and do not run a campaign. According to the Table 11 , it is possible to state that the campaigns of competitors has no effect on the net sales and gross income of the firms concerned. This situation should be analyzed in the light of the fact that the advertisement of a firm has a boosting effect on the visits to the firms in the same region and that the firms can very quickly copy each other's campaigns with the intelligence.

Table 11: Wilcoxon Rank Test for Measuring the Effect of the Campaigns of Competitors on the Net Sales and Gross Income

\begin{tabular}{ccc}
\hline Campaigns of Competitors & Gross Income (Mean Value-TL) & Net Sales (Mean Value) \\
\hline No & 2494937 & 8,1 \\
\hline Yes & 2463640 & 7,619048 \\
\hline W & Wilcoxon Rank Test & 220,5 \\
\hline P Value & 219 & 0,8067
\end{tabular}

In the days when the digital marketing expenditures were made, it was examined whether the net sales and gross incomes have changed and the results in the Table 12 were obtained. As can be seen in the Table 12, the sales and gross income increased considerably during the days when the digital marketing expenditures were made. Especially in the light of recently developed artificial intelligence applications, that the smart phones can identify the consumer's preferences and profiles and offer appropriate products are highly effective. It should not be forgotten that the digital advertisements are dynamic in this framework, rather than static, and use the smart algorithm engines. Therefore, it is expected that the search engines havingthe developed software technology and the more efficient algorithms will be more effective and more preferred in the future.

Table 12: Effect of the Digital Marketing Expenditures on the Net Sales and Gross Income

\begin{tabular}{ccc}
\hline Digital Marketing & Gross Income (Mean Value-TL) & Net Sales (Mean Value) \\
\hline No & $1,920,402$ & 6.3125 \\
\hline Yes & $3,348,470$ & 9.95 \\
\hline
\end{tabular}

The Wilcoxon Rank test was applied, and it was tested whether the difference between the days when the digital marketing expenditures were made and not made was statistically significant. As seen in the Table 13, it is possible to state that there is a statistically significant difference in the digital marketing expenditures in terms of the net sales and gross income. Digital marketing campaigns create a boost effect on the net sales and gross income.

Table 13: Wilcoxon Rank Test for Measuring the Effect of the Digital Marketing Expenditures on the Net Sales and Gross Income

\begin{tabular}{ccc}
\hline Digital Marketing & Gross Income (Mean Value-TL) & Net Sales (Mean Value) \\
\hline No & $1,920,402$ & 6.3125 \\
\hline Yes & $3,348,470$ & 9.95 \\
\hline W & Wilcoxon Rank Test & 473.5 \\
\hline P Value & 485 & 0.003756 \\
\hline
\end{tabular}


It was desired to measure the difference between the net sales and gross income on the days when the billboard advertisements were made and the net sales and gross income on the other days, and the results in the Table 14 were obtained. As seen in the Table 14, the billboard advertisements did not have a boost effect on the net sales and gross income in the days when the billboards were posted. The Wilcoxon Rank test was applied to test whether this effect was statistically significant.

Table 14: Effect of the Billboard Expenditures on the Net Sales and Gross Income

\begin{tabular}{ccc}
\hline Billboard Expenditures & Gross Income (Mean Value-TL) & Net Sales (Mean Value) \\
\hline No & $3,806,111$ & 11.28 \\
\hline Yes & $1,232,204$ & 4.407407 \\
\hline
\end{tabular}

It is possible to state that the billboard expenditures make a statistically significant difference in terms of the net sales and gross income. Billboard advertisements alone were not able to increase the sales. It is possible to state that once the billboard advertisements are terminated and the other mediums are introduced the sales rise upwards. The explanation of this situation may be that the outdoor billboards are usually in such places where the traffic is heavy, they are overlooked when the traffic runs fast, and they are not within the consumer's psychological area of interest during the traffic congestion. Digital marketing, on the other hand, coincides with the time the consumer chooses and is most comfortable in terms of psychology and attention.

Table 15: Wilcoxon Rank Test for Measuring the Effect of the Billboard Expenditures on the Net Sales and Gross Income

\begin{tabular}{ccc}
\hline Billboard Expenditures & Gross Income (Mean Value-TL) & Net Sales (Mean Value) \\
\hline No & $3,806,111$ & 11.28 \\
\hline Yes & $1,232,204$ & 4.407407 \\
\hline W & Wilcoxon Rank Test & 63 \\
\hline P Value & 29 & 0.000005
\end{tabular}

As it is understood in the analysis above, the digital marketing campaigns have a significant effect on the sales and gross income. The fact that the digital marketing campaigns also support other marketing campaigns is inevitable. Therefore, the correlations between the total marketing expenditures and the net sales and gross income were examined. First, the relationship between two variables was visualized with scatter plots.

Figure 1: Relationship between the Total Marketing Expenditures and the Net Sales and Gross Income
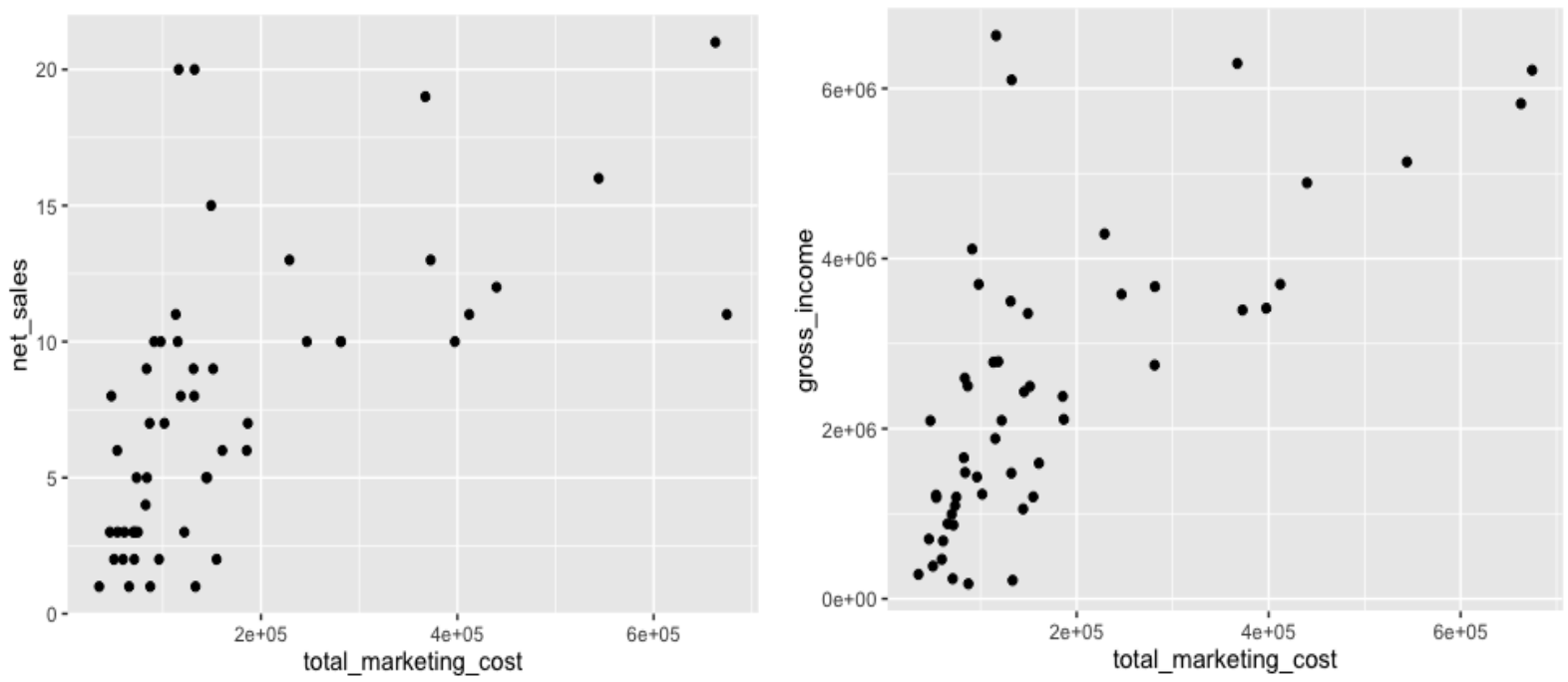
As seen in the Figure 1, it is possible to state that there was a very high and positive correlation between the two variables.

Table 16: Correlation Matrix for the Total Marketing Expenditures and the Net Sales and Gross Income

\begin{tabular}{|c|c|c|c|c|}
\hline & Total Marketing Cost & $\begin{array}{c}\text { Main Newspaper } \\
\text { Brand Cost }\end{array}$ & $\begin{array}{c}\text { Other Newspaper } \\
\text { Brand Cost }\end{array}$ & $\begin{array}{c}\text { Newspaper Brand } \\
\text { Cost Total }\end{array}$ \\
\hline $\begin{array}{l}\text { Gross Income (Mean } \\
\text { Value-TL) }\end{array}$ & $0.7 * * *$ & $0.29 * *$ & $0.45^{* * *}$ & $0.34 * *$ \\
\hline $\begin{array}{l}\text { Net Sales (Mean } \\
\text { Value) }\end{array}$ & $0.61 * * *$ & $0.28 * *$ & $0.43^{* * *}$ & $0.35^{* *}$ \\
\hline
\end{tabular}

According to the Table 16, it can be mentioned that there was a statistically significant correlation of 0.7 between the total marketing expenditures and the gross income and there was a strong positive correlation between the two variables. According to the Table 16, it can be mentioned that there was a statistically significant correlation of approximately 0.61 between the total marketing expenditures and the net sales and there was a strong positive correlation between the two variables. According to the correlation analysis, it can be mentioned that there was a statistically significant correlation of approximately 0.28 between the advertising expenses spent on the main newspaper and the net sales and there was a poor positive correlation between the two variables. Similarly, it can be mentioned that there was a statistically significant correlation of approximately 0.29 between the advertising expenses spent on the main newspaper and the gross income and there was a poor positive correlation between the two variables. It can be mentioned that there was a statistically significant correlation of approximately 0.43 between the advertising expenses spent on the other newspapers and the net sales and there was a medium positive correlation between the two variables. Similarly, it can be mentioned that there was a statistically significant correlation of approximately 0.45 between the advertising expenses spent on the other newspapers and the gross income and there was a medium positive correlation between the two variables. It can be mentioned that there was a statistically significant correlation of approximately 0.35 between the advertising expenses spent on all newspapers and the net sales and there was a medium positive correlation between the two variables. Similarly, it can be mentioned that there was a statistically significant correlation of approximately 0.34 between the advertising expenses spent on all newspapers and the gross income and there was a medium positive correlation between the two variables.

Impulse/response analyses were conducted to better examine the relationships between the dependent and independent variables. First, VAR models were created to conduct Impulse/ Response analyses. The selection of lag is important to create a VAR model. The following variables were included in the VAR model: "Square meter price, Average temperature, Cost of advertising in the main newspaper, Cost of advertising in the other newspapers, Advertising on TV and its cost, Cost of advertising on the thematic (news) TV channels, Digital advertising cost, Cost of advertising on the billboard, Total marketing cost, Net housing sales and Gross sales turnover."

The effect of digital marketing expenditures on the gross income is shown in the Figure 2. Digital marketing expenditures had a serious effect on the gross income until the 2 nd week and then lost its effect. At this point, if the digital marketing expenditures are to be made, it will be advantageous to periodically change the digital marketing campaigns in maximum two weeks. The probable reason for this is that the digital marketing is very dynamic and that the consumer can only pay attention to the most current and new/different situations while spending time in the digital environment.

Figure 2: Response of the Gross Income to the Digital Marketing Expenditures

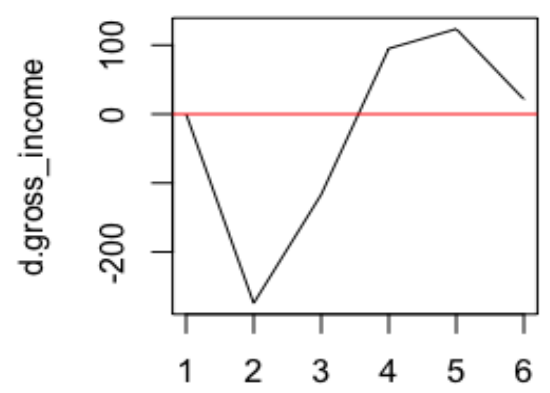


The effect of TV marketing expenditures on the gross income is shown in Figure 3.TV marketing expenditures had a serious effect on the gross income until the 2 nd week and then lost its effect. At this point, it may be advisable that TV marketing expenditures are made in parallel times with the digital marketing, or that there is not too much time lag between them, and that the campaigns with parallel content are arranged in both mediums.

\section{Figure 3: Response of the Gross Income to the TV and Marketing Expenditures}

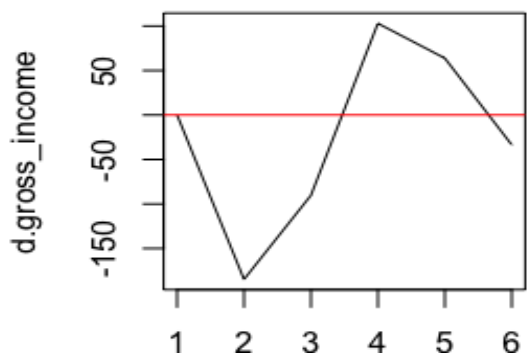

The effect of all marketing expenditures on the gross income is shown in the Figure 4. All marketing expenditures had a serious effect on the gross income until the 2 nd week and then lost its effect. At this point, it is very important to optimize the time intervals when making the marketing expenditures.

Figure 4: Response of the Gross Income to the Total Marketing Expenditures

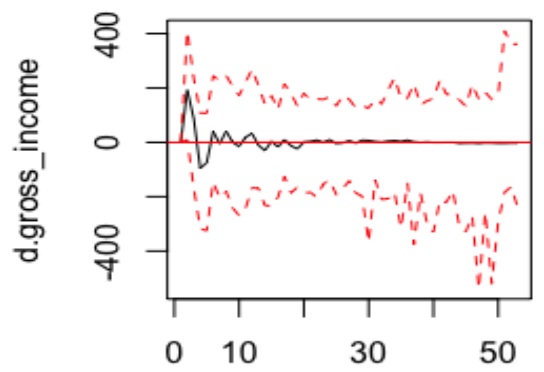

$95 \%$ Bootstrap Cl, 100 runs

The effect of all marketing expenditures on the net sales is shown in the Figure 4. All marketing expenditures had a serious effect on the net sales until the 2 nd week and then lost its effect. At this point, it is very important to optimize the time intervals when making the marketing expenditures.

Figure 5: Response of the Net Sales to the Total Marketing Expenditures

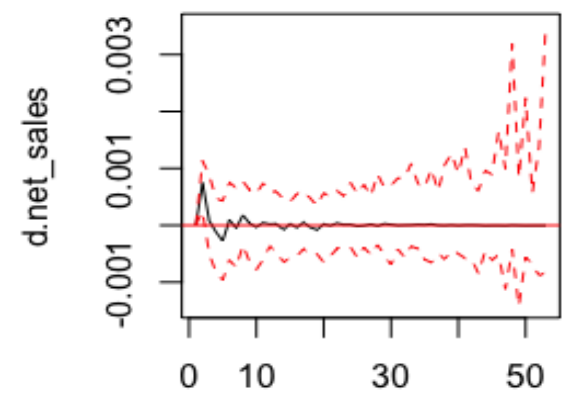

95 \% Bootstrap Cl, 100 runs 
After analyzing the relationship between the marketing expenditures and the sales, it was desired to model to what extent these expenditures affected the net sales. Because the net sales were a discrete variable, the generalized linear models were used and when the modeling is carried out, the distribution must come from the discrete distribution families. For this reason, it was tested whether the net sales comply with the two largest candidate Poisson and negative binomial distributions.

\section{Figure 6: Q-Q Pot for the Net Sales}

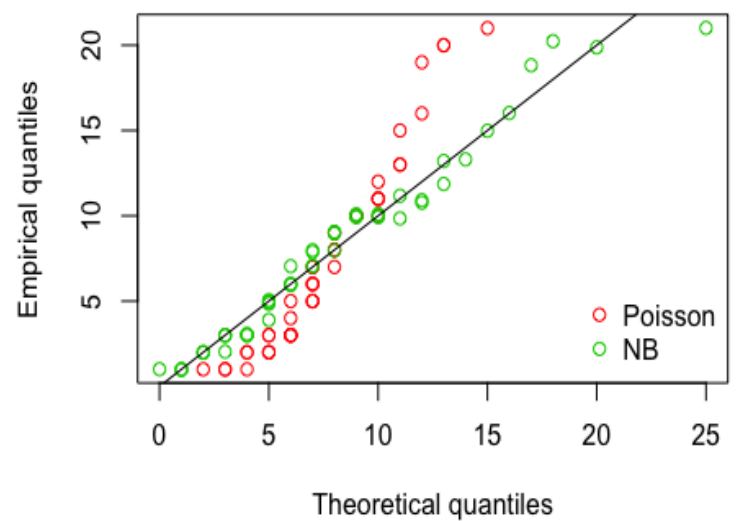

As seen in the Figure 6, the net sales seem to fit to the negative binomial distribution. Now, the generalized linear model can be constructed using the negative binomial distribution family. The model results are given below. The marketing expenditures on the main newspaper create more effect on the net sales than the other newspapers. The digital marketing expenditures are the most effective. They are followed by Hürriyet newspaper, other newspapers, and TV expenditures, respectively.

Table 17: Results of the Negative Binomial Regression Model Constructed for the Factors Affecting the Net Sales

\begin{tabular}{lrrrr}
\hline & Digital Marketing Cost & TV Cost & Other Newspaper Brand Cost & Main Newspaper Brand Cost Total \\
\hline Coeff. & 0.0000425 & 0.0000322 & 0.0000124 & 0.00001891 \\
\hline Srd. Error & 0.00000218 & 0.00000127 & 0.00000412 & 0.000003172 \\
\hline T & 1.951 & 2.534 & 2.73 & 5.961 \\
\hline P Value & 0.05686 & 0.01461 & 0.00882 & 0.0000 \\
\hline
\end{tabular}

\section{CONCLUSION}

Due to its demographic structure, its need for urban transformation, and being a growing economy in the category of developing countries; Turkey is a market that has a continuous new housing demand/need. Although the basic dynamics are in favor of the producers in such markets, there are also times when the economy slows down and the competition rises. Especially in such times, in general at all times, the correctly selecting the marketing methods and the channels used by the housing firms (being optimal in terms of cost benefit) can highly affect the sales success of the firms. Therefore, the marketing strategies that the housing developers will implement at the right time and on the right channel will be able to positively distinguish their projects from the competitors. Within the scope of this study; R programming language and Wilcoxon Rank was used to analyze the different housing marketing campaigns of one of the pioneer real estate firms in Turkey and their effect on the sales figures; the rank sum test was conducted; and, the VAR models were constructed and Impulse Response analysis, Pearson Correlation Coefficient were used for the relationship analyses. According to the results of the study, it is seen that the social events, long-term holidays, rainfall and snowfall, campaigns of the competitors have no statistically significant effect on the net sales and gross income. However, it was determined that the Ramadan period and the digital marketing had a significant effect on the net sales and gross income. It is determined that the use of outdoor billboard, which is expected to affect the housing sales, was inversely proportional to the net sales and gross income, that is, it had a negative effect when applied. According to the correlation analysis, it was observed that there was a strong positive correlation between the total marketing expenditures and the gross income and net sales, that there was a poor positive correlation between the advertising expenses spent on the main newspaper and the net sales and gross income, that there was a medium positive correlation between the advertising expenses spent on the other newspapers and the net sales and gross income, that there was a medium positive correlation between the advertising expenses spent on all newspapers and the net sales and gross income. It was concluded that it would be advantageous that the digital marketing campaigns are launched in maximum two-week periods that the 
advertisements appearing on TV are launched at the same or near time with the digital marketing campaigns, that the time intervals of all marketing expenditures are optimized.

In the last phase of the study, the binomial distributions were used, and it was determined that the most effective marketing channel was the digital marketing. This is followed by the main newspaper, other newspapers, and TV expenditures, respectively. It is thought that this study can be more improved as a result of including the followings into the model: more detailed classification of the social events, remodeling the Ramadan periods according to either they coincide with the summer month or the winter month, assessment of the effect of rainfall and snowfall considering the climate zone Turkey is in, more detailed analysis of the effect of the campaign of competitors, that the effect of digital marketing will be higher as the technology develops. It is expected that the modeling of the findings reached in this study (or which will be detailed in later studies) by using an algorithm will provide a cost-benefit optimization.

\section{REFERENCES}

Cengel, O. (2006). Emerging marketing techniques in the real estate sector and current implications. İstanbul Ticaret Üniversitesi Sosyal Bilimler Dergisi, 5(9), 125-131.

Chin, H. C., Quddus, M. A. (2003). Modeling count data with excess zeroes - an empirical application to traffic accidents. Sociological Methods \& Research, 32(1), 90-116.

Cizmeci, F., Ercan, T. (2015). The effect of digital marketing communication tools in the creation brand awareness by housing companies. Megaron, 10(2), 149-161.

Kerby, D. S. (2014). The Simple Difference Formula: An Approach to Teaching Nonparametric Correlation 1. Comprehensive Psychology, 3(11).

Komurlu, R. et al. (2013). Drivers of residential developers' marketing strategies based on buyer preferences. METU Journal of the Faculty of Architecture, 30(2), 1-16.

Miles, M., Berens, G. and Weiss, M. (2001), Real Estate Development: Principles and Process, Urban Land Institute, Washington, DC

Pesaran, H. Hashem, and Yongcheol Shin. (1998). Generalized impulse response analysis in linear multivariate models. Economics letters, 58(1), 17-29.

Polat, S., Ferman, M. (2015). An analysis of factors affecting understanding and applications of branded housing project marketing around the Istanbul metropolitan area. Journal of Management, Marketing and Logistics, 2(1), 24-36.

PWC, (2015, February) The World in 2050.

Stigler, S. M. (1989). Francis Galton's Account of the Invention of Correlation. Statistical Science, 4(2), 73-79

Terri, T. (2003). Fair Housing Marketing Strategy and Materials Development, Request for Proposals, Arizona Department of Housing, Phoenix, AZ.

TUIK (Turkish Statistical Institute). House Sales Statistics. Retrieved form http://www.tuik.gov.tr/PreTablo.do?alt_id=1056.

TUIK (Turkish Statistical Institute). Household Stats. Retrieved from http://www.tuik.gov.tr/PreHaberBultenleri.do?id=18624.

TUIK (Turkish Statistical Institute). Population Stats. Retrieved from http://www.tuik.gov.tr/PreHaberBultenleri.do?id=18616.

TUIK Retrieved from https://biruni.tuik.gov.tr/gosterge/?locale=en.

TUIK Retrieved from http://web.archive.org/web/20160104210603

Worldbank, Statistics about Turkey. Retrieved from http://data.worldbank.org/country/turkey.

Zeileis, A., Kleiber, C. and Jackman, S. (2008). Regression Models for Count Data in R, Journal of Statistical Software, July 2008, Volume 27, Issue 8:1-25.

Zivot, E. and Jiahui, W. (2006). Vector autoregressive models for multivariate time series. Modeling Financial Time Series with S-Plus ${ }^{\circledR}$, $385-429$. 